\title{
Etno-educación: esencialismo étnico o republicanismo popular
}

Ethno-education: ethnic essentialism or popular republicanism

Etnoeducação: essencialismo étnico ou republicanismo popular

José Figueroa, Ecuador

Universidad Central del Ecuador/jafigueroa@uce.edu.ec

Chasqui. Revista Latinoamericana de Comunicación

N. ${ }^{\circ} 142$, diciembre 2019 - marzo 2020 (Sección Diálogo de saberes, pp. 223-246)

ISSN 1390-1079 / e-ISSN 1390-924X

Ecuador: CIESPAL

Recibido: 15-11-2019/Aprobado: 27-03-202O 


\section{Resumen}

El presente artículo explora desde 2 experiencias de educación intercultural los límites del esencialismo étnico y las posibilidades epistemológicas y políticas que tendría para la superación de estos límites el reconocimiento de propuestas educativas cercanas al republicanismo popular de matriz indígena. A partir del contraste entre el proceso de evaluación y cierre de la Universidad Intercultural de Pueblos y Nacionalidades Amawtay Wasi, -desde ahora UINPI-, y la historia social del Instituto intercultural Quilloac se sostiene que la visibilización de las tradiciones republicanas de los sectores marginados por razones raciales, económicas o de género, constituye una alternativa al esencialismo étnico característico de las propuestas de etnoeducación dominadas por el neoliberalismo y el posmodernismo y constituye una pieza clave en la construcción de un estado plurinacional. En el caso del instituto Quilloac, las tradiciones republicanas se hacen visibles en la articulación que hicieron los indígenas entre la lucha contra la hacienda y unas demandas por una educación intercultural pertinente y de calidad. En este contexto, la lucha por la educación cuestionó los legados de la dominación hacendataria y legitimó una serie de reclamos que a la par que defendían las especificidades de los pueblos y nacionalidades reclamaban por una inserción democrática de los indígenas a la sociedad nacional. Como veremos la lucha recurrió a un capital democrático radical popular, propio de las tradiciones republicanas.

Palabras clave: educación intercultural, esencialismo étnico, matriz indígena

\section{Abstract}

The present article explores from 2 experiences of intercultural education the limits of ethnic essentialism and the epistemological and political possibilities that the recognition of educational proposals close to popular republicanism of indigenous matrix would have for overcoming these limits. Based on the contrast between the process of evaluation and closure of the Intercultural University of Peoples and Nationalities Amawtay Wasi, -now UINPI-, and the social history of the Intercultural Institute Quilloac, it is argued that the visibility of the republican traditions of the sectors marginalized by racial, economic or gender reasons, constitutes an alternative to the ethnic essentialism characteristic of the ethnoeducation proposals dominated by neoliberalism and postmodernism and constitutes a key piece in the construction of a plurinational state. In the case of the Quilloac Institute, republican traditions are visible in the articulation made by indigenous people between the fight against the hacienda and demands for relevant and quality intercultural education. In this context, the struggle for education questioned the legacies of the landowning domination and legitimized a series of claims that, at the same time that they defended the 
specificities of peoples and nationalities, demanded for a democratic insertion of indigenous people into national society. As we will see, the struggle resorted to a popular radical democratic capital, typical of republican traditions..

Keywords: intercultural education, ethnic essentialism, indigenous matrix

\section{Resumo}

O presente artigo explora, a partir de duas experiências de educação intercultural, os limites do essencialismo étnico e as possibilidades epistemológicas e políticas que o reconhecimento de propostas educacionais próximas ao republicanismo popular da matriz indígena teria para superar esses limites. Do contraste entre o processo de avaliação e fechamento da Universidade Intercultural de Povos e Nacionalidades Amawtay Wasi, agora UINPI, e a história social do Instituto Intercultural Quilloac, argumenta-se que a visibilidade das tradições republicanas dos setores marginalizados por razões raciais, econômicas ou de gênero, constituem uma alternativa ao essencialismo étnico característico das propostas de etnoeducação dominadas pelo neoliberalismo e pós-modernismo e constituem peça fundamental na construção de um estado plurinacional. No caso do Instituto Quilloac, as tradições republicanas são visíveis na articulação feita pelos povos indígenas entre a luta contra a fazenda e as demandas por educação intercultural relevante e de qualidade. Nesse contexto, a luta pela educação questionou os legados da dominação fundiária e legitimou uma série de reivindicações que, ao mesmo tempo em que defendiam as especificidades de povos e nacionalidades, exigiam uma inserção democrática dos povos indígenas na sociedade nacional. Como veremos, a luta recorreu a uma capital democrática radical popular, típica das tradições republicanas.

Palabras chave: educação intercultural, essencialismo étnico, matriz indígena

\section{Introducción}

El presente artículo explora desde 2 experiencias de educación intercultural los límites del esencialismo étnico y las posibilidades epistemológicas y políticas que tendría para la superación de estos límites el reconocimiento de propuestas educativas cercanas al republicanismo popular de matriz indígena. A partir del contraste entre el proceso de evaluación y cierre de la Universidad Intercultural de Pueblos y Nacionalidades Amawtay Wasi, -desde ahora UINPI-, y la historia social del Instituto intercultural Quilloac se sostiene que la visibilización de las tradiciones republicanas de los sectores marginados por razones raciales, económicas o de género, constituye una alternativa al esencialismo étnico característico de las propuestas de etnoeducación dominadas por el neoliberalismo y el posmodernismo y constituye una pieza clave en la construcción de un estado plurinacional. En el caso del instituto Quilloac, las tradiciones republicanas se hacen visibles en la articulación que hicieron 
los indígenas entre la lucha contra la hacienda y unas demandas por una educación intercultural pertinente y de calidad. En este contexto, la lucha por la educación cuestionó los legados de la dominación hacendataria y legitimó una serie de reclamos que a la par que defendían las especificidades de los pueblos y nacionalidades reclamaban por una inserción democrática de los indígenas a la sociedad nacional. Como veremos la lucha recurrió a un capital democrático radical popular, propio de las tradiciones republicanas (Sanders, 2009; Coronel, en prensa; Mendez, 2005; Coronel y Cadahia, 2018; Guanche, 2017)

El artículo muestra cómo en el caso de la UINPI, la coincidencia de los intereses corporativos de un sector de la dirigencia indígena y de los sectores neoliberales en el poder, permitió la fundación de una Universidad de Pueblos y Nacionalidades, de carácter privado y económicamente insostenible, lo que se tradujo en un deterioro institucional recubierto de retóricas de particularismo cultural. El artículo analiza cómo la exaltación de la diferencia cultural en un contexto posmoderno y neoliberal, se convierte en un eficiente mecanismo de marginación económica y política de los pueblos y nacionalidades. En este sentido, el artículo muestra cómo, a pesar del deterioro del proyecto de la universidad tanto en términos de entorno de aprendizaje como de resultados de aprendizaje, un grupo de intelectuales nacionales e internacionales concibieron a la UINPI como una alternativa a la supuesta decadencia de la Universidad Occidental y definieron su evaluación y cierre como resultado de la imposición del monoculturalismo del Estado nacional y del autoritarismo de Rafael Correa.

En contraste, la historia del Instituto Quilloac de Cañar, muestra cómo la articulación de las luchas contra la dominación hacendataria y contra el racismo y a favor de una educación democrática y pertinente, saca a la luz una agenda construida con un sentido republicano alternativo al particularismo y al esencialismo etnicista, defendido por el neoliberalismo posmoderno. La historia del instituto muestra la articulación de las luchas por los intereses específicos de los pueblos y nacionalidades a los intereses locales y nacionales; de manera especial, la biografía intelectual de Jose Antonio Quinde, uno de los dirigentes de Quilloac, sintetiza la articulación de las luchas contra el analfabetismo, el racismo y la dominación hacendataria, entre los indígenas. A diferencia de los teóricos posmodernos que confunden analfabetismo con oralidad y enclaustran a los indígenas en el ámbito de lo particular, los indígenas de Quilloac, articularon la lucha contra la dominación hacendataria a las demandas por una educación intercultural de calidad, democrática y pertinente. En este proceso cuestionaron el analfabetismo impuesto por la hacienda mientras exigían una inserción democrática al estado nacional, sin olvidar sus especificidades como pueblos y nacionalidades.

La noción de republicanismo popular ha ido adquiriendo un potente estatuto académico y político, en las últimas décadas. Los campos de la historia social y la filosofía política han ofrecido contribuciones muy importantes, al privilegiar el estudio de momentos revolucionarios en los que se evidencia el 
papel protagónico de los sectores populares en la construcción de propuestas democrático-radicales (Coronel, en prensa; Sanders, 2009; Méndez, 2005), así como las tensiones y debates con las tendencias republicanas oligárquicas y conservadoras (Domenech, 2017; Guanche, 2017). Algunos estudios visibilizan el papel que los sectores populares han tenido en la conformación de bloques plurales que cobijan la etnicidad, las perspectivas de clase y género o las demandas específicas que formulan en tanto actores sociales y políticos (Figueroa, 2009, Méndez, 2005), mientras otros enfoque indagan en el papel de los sectores populares en las configuraciones del estado, y los modos como los proyectos estatales son apropiados y resignificados por los sectores populares (Coronel, en prensa; Sanders, 2009; Coronel y Cadahia. 2018, Guanche, 2018).

La constitución del 2008 define al Ecuador como un "Estado constitucional de derechos y justicia, social, democrático, soberano, independiente, unitario, intercultural, plurinacional y laico", y la educación intercultural es uno de los puntos estratégicos de las luchas de los pueblos y nacionalidades a favor del reconocimiento de sus derechos. Como lo demuestra el caso de la Amawtay Wasi, algunos de los sectores esencialistas establecen una distancia radical e insalvable entre los pueblos y nacionalidades y los estados nacionales, lo que se traduce en la construcción de un particularismo que abandona la lucha por la transformación social y termina privilegiando a unas pequeñas élites del movimiento indígena. Por el contrario, la visibilización de las tradiciones republicanas del movimiento indígena permiten recuperar los legados democrático radicales de los sectores populares que apuestan por la construcción de un estado plurinacional e intercultural a la vez que reclaman por la transformación de las herencias provenientes del interno colonialismo y que se manifiestan en las instancias nacionales, regionales y locales.

$\mathrm{Al}$ introducir categorías republicanas al debate de la educación intercultural se descubren elementos que permiten imaginar un estado plurinacional e intercultural que reconozca la existencia de un "todos" en tanto elemento constitutivo de la comunidad política (Guanche, 2017), al tiempo que visibiliza la importancia estratégica de los intereses y dinámicas específicos de los pueblos y nacionalidades insertos en el estado nacional. El esencialismo étnico que presupone una distancia ontológica insalvable entre los pueblos indígenas y los estados nacionales abandona la lucha por una nueva hegemonía, evita construir solidaridades populares y elimina la posibilidad de llevar la educación intercultural al plano nacional. En contraste el reconocimiento de las tradiciones republicanas de pueblos y nacionalidades y su articulación con las dinámicas particulares permite concebir un nuevo modo de hegemonía en el que se combinen los principios de igualdad fundamentales para la convivencia social, con las particularidades que caracterizan a las comunidades específicas. 


\section{Etnoeducación, particularismo y neoliberalismo en Ecuador: el caso de la Amawtay Wasi.}

La UINPI fue uno de los experimentos de etnoeducación que se llevaron a cabo en el Ecuador en pleno auge del neoliberalismo. Como quisiera mostrar, la compleja historia de la UINPI, desde su creación hasta su eliminación del sistema de educación superior ecuatoriano, muestra la convergencia del neoliberalismo, la exaltación radical de la diferencia, el particularismo cultural y la profundización de la exclusión socioeconómica de los pueblos y nacionalidades.

La UINPI fue aprobada mediante la Ley 40 del 5 de agosto del 2004 promulgada por el Congreso Nacional y se creó como institución particular, autofinanciada, de derecho privado, bajo el patrocinio de la Confederación de Nacionalidades Indígenas del Ecuador -CONAIE- y del Instituto Científico de Culturas Indígenas ICCI. Su existencia jurídica terminó el 4 de noviembre de 2013 cuando fue suspendida por el Consejo de Educación Superior-CES- luego de no haber alcanzado el puntaje mínimo en el proceso de evaluación implementado por el Consejo de Evaluación, Acreditación y Aseguramiento de la Calidad de la Educación Superior-CEAACES-. De un total de 100 puntos, la Universidad recibió 26,9 , cuando se requería obtener al menos 40 para continuar de manera condicionada y 60 para mantenerse de manera regular.

La Universidad, concebida como uno de los proyectos emblemáticos de la CONAIE, fue una de las instituciones de educación creadas en el contexto de la desregulación neoliberal y fue evaluada de acuerdo a disposiciones emanadas de un nuevo marco constitucional y una nueva Ley Orgánica de Educación Superior que buscaba recuperar el rol regulador del estado. En su corta existencia, la universidad tuvo que enfrentar complejidades estructurales, como sucedió con su reconocimiento como institución privada por parte del estado y la aceptación de esa condición por parte de la CONAIE y el ICCI, como organismos proponentes, a pesar de que estaba dirigida prioritariamente a los indígenas que conforman los quintiles poblacionales de más bajos recursos económicos en el país. Además de la limitación estructural de su condición de universidad privada, otra razón del fracaso de este proyecto estratégico se encuentra en un culturalismo particularista que imposibilitó la construcción de un modelo educativo capaz de combinar calidad y derechos políticos. Como veremos, el culturalismo se convirtió en una estrategia discursiva que escondía un deterioro estructural de aspectos medulares como el profesorado, la investigación o la infraestructura.

De hecho, la exaltación del particularismo cultural involucraba el cuestionamiento a la misma evaluación implementada por el estado bajo el argumento de que ésta se hacía bajo categorías coloniales, lo que se convirtió en un argumento favorable a la marginación de las IES interculturales de la noción de calidad. Como veremos, un grupo de culturalistas acusaron al estado de impulsar una evaluación hecha bajo parámetros coloniales, sin tomar en cuenta 
que el modelo de la Amawtay Wasi reconoció los elementos idiosincráticos de los pueblos y nacionalidades anunciados por la institución, así como las disposiciones nacionales e internacionales que los respaldan, al tiempo que el estado asumía las responsabilidades económicas y sociales de la educación, mediante un marco institucional que apuesta por la defensa de los derechos de todos los estamentos que conforman las instituciones de Educación Superior. La evaluación de la Amawtay Wasi se basó, entre otras disposiciones legales, en el Convenio 169 de la Organización Internacional del Trabajo que en los numerales 1 y 3 del artículo 27 sostiene:

1. Los programas y los servicios de educación destinados a los pueblos interesados deberán desarrollarse y aplicarse en cooperación con estos a fin de responder a sus necesidades particulares, y deberán abarcar su historia, sus conocimientos y técnicas, sus sistemas de valores y todas sus demás aspiraciones sociales, económicas y culturales ... “, "3. Además, los gobiernos deberán reconocer el derecho de esos pueblos a crear sus propias instituciones y medios de educación, siempre que tales instituciones satisfagan las normas mínimas establecidas por la autoridad competente en consulta con esos pueblos. Deberán facilitárseles recursos apropiados para tal fin .

La evaluación de la UINPI contempló aspectos administrativos mínimos indispensables para el cumplimiento de la misión institucional, al tiempo que aplicó una perspectiva intercultural que reconocía sus especificidades idiosincráticas como la administración y la veeduría comunitarias, los centros de saber, junto a temas universales como las condiciones de empleo de los profesores, la estabilidad y las condiciones mínimas para una carrera docente digna, etc.

La evaluación de la universidad inició con la expedición del Mandato 14 dictado por la Asamblea Nacional Constituyente el 22 de Julio del 2008, cuando se encontraba deliberando en Montecristi con miras a la elaboración de la nueva Constitución ecuatoriana. Uno de los puntos más delicados que enfrentó la Asamblea fue el deterioro del sistema de educación superior, en el que varias instituciones habían desvirtuado la noción de autonomía universitaria deviniendo en entidades autárquicas que permitieron la existencia de escandalosos casos de corrupción, incluida la compra y venta de títulos. El caso más conocido fue el de la Universidad Cooperativa de Colombia que obligó a la Asamblea Constituyente a promulgar el Mandato 14, mediante el cual se requería al entonces organismo evaluador nacional -CONEA- presentar un detallado reporte sobre la situación del sistema universitario nacional y dio el plazo de un año para evaluar las 71 universidades que conformaban el sistema nacional de educación superior.

En cumplimiento del Mandato 14, entre Junio y octubre del 2009, el CONEA evaluó las Instituciones de Educación Superior -IES-, que fueron categorizadas de acuerdo a los resultados en cinco niveles que iban de la A a la E. Una vez 
realizada la evaluación, un total de 26 universidades, incluida la UINPI quedaron en la categoría más baja por razones como la precaria situación de los docentes, de la investigación, de las publicaciones y de la infraestructura.

Con miras a una depuración del sistema, la Ley Orgánica de Educación Superior, expedida en Octubre del 2010, estableció que las universidades ubicadas en la categoría E se evaluaran en un añoy medio después dela expedición de la Ley. El nuevo Consejo de Evaluación, Acreditación y Aseguramiento de la Calidad de la Educación Superior, CEAACES, se instaló el 29 de agosto del 2011 y de inmediato empezó el proceso de evaluación de las universidades ubicadas en la categoría E. Respecto a la UINPI, en el proceso de evaluación se implementaron una serie de medidas específicas a la institución como “...visitas y diálogos con las principales instancias directivas de la universidad; revisión y análisis de material técnico-institucional de la Universidad; coordinación con el SNIESE, para modificar los formularios de datos; aprobación de lineamientos y normas interculturales para la evaluación; modificación general del modelo de evaluación incluyendo criterios, subcriterios, parámetros e indicadores de carácter intercultural". (Resolución 003-0026 25 CEAACES-2012).

La evaluación recogió las disposiciones del Convenio 169 de la Organización Internacional del Trabajo, respecto a la aplicación de “... principios, criterios y procedimientos con perspectiva intercultural, según la cultura y la cosmovisión de los pueblos y nacionalidades indígenas que participan de sus programas y carreras"; una gran parte de la responsabilidad recayó en académicos indígenas como lo muestra el equipo de evaluadores conformado por dos profesionales quichuahablantes y un lingüista, todos de gran trayectoria profesional; además, durante todo el proceso se mantuvieron contactos y reuniones permanentes con las directivas de la UINPI, hubo reuniones de su Rector y el presidente del CEAACES, se crearon una serie de criterios, subcriterios, parámetros e indicadores de carácter intercultural que sirvieron para evaluar los componentes institucionales, académicos y la infraestructura de la UINPI. De igual modo, los criterios de interculturalidad funcionaron como referente para que el Sistema Nacional de Información de la Educación Superior del Ecuador (SNIESE) adaptara los parámetros de incorporación de datos a los criterios de la UINPI.

A pesar de que los resultados de esta primera evaluación fueron desfavorables para la UINPI, el CEAACES, una vez conoció y analizó el informe técnico, en sesión extraordinaria del 11 de abril del 2012, resolvió que los resultados no eran lo suficientemente concluyentes en términos interculturales. En estas condiciones se decidió prorrogar 12 meses más el proceso de evaluación con el compromiso de establecer los estándares mínimos de calidad que debía tener la UINPI y de resguardar los derechos de los pueblos y nacionalidades.

A partir del reconocimiento de la importancia que tiene para el país y para los pueblos y las nacionalidades la implementación de un sistema universitario que combine calidad y derechos, el CEAACES inició una investigación a profundidad 
con el objetivo de incorporar los insumos necesarios para elaborar un modelo de evaluación que respondiera a los intereses de ambos sectores. El proceso de investigación también estuvo encaminado a detectar los insumos para la elaboración de unos exámenes interculturales, lo cual no tenía precedente en la historia del país.

La investigación de campo exploró la historia institucional, la pertinencia social y económica de la UINPI y se recabó información curricular y lingüística para la evaluación, mediante un equipo formado por profesionales Quichua y Shuar, dirigidos por un lingüista quichua hablante, Ph.D, profesor de Madison, y el suscrito, como miembro del Consejo que presidía la comisión de evaluación. En la investigación de campo se realizaron una serie de visitas a las extensiones de la UINPI ubicadas en territorio: las chacracuna (en quichua es el plural de chacra, significa tierra arable y es el nombre con el que se designa a las extensiones) de Tenta, ubicada en Saraguro, Loja; de La Esperanza, ubicada en el cantón de Pedro Moncayo, Pichincha, y la de Conocoto, ubicada en el Distrito Metropolitano de Quito, Pichincha; además de la Ajaa, (nombre que significa huerto en Shuar Chicham), ubicada en Chiguaza, cantón Huamboya, provincia Morona Santiago.

La investigación dio insumos para la elaboración de los dos instrumentos de evaluación aplicados en la segunda fase por parte del CEAACES: 1 el modelo de evaluación del entorno de aprendizaje, que buscaba detectar si la institución cumplía las condiciones mínimas que garantizaran el desempeño de los procesos de enseñanza-aprendizaje 2 evaluación de los resultados de aprendizaje a través de un examen que buscaba detectar el manejo de competencias mínimas por parte de los estudiantes que habían cubierto el 80\% de los créditos de la carrera. El entorno de aprendizaje fue evaluado con una metodología de decisión multicriterio, contempló elementos técnicos y jurídicos y la interculturalidad fue concebida como un eje transversal y específico, ya que en el modelo, de un total de 50 indicadores, 11 fueron específicamente interculturales (CEAACES, Informe Final, p 10, 2013).

El modelo de evaluación del entorno de aprendizaje tuvo cuatro grandes ejes: Academia, Institucional, Ámbitos de Aprendizaje y Soporte Pedagógico. Quiero concentrarme en el caso de la situación de los profesores en el eje Academia porque muestra cómo el discurso culturalista puede convertirse en un justificativo de la degradación profesional y humana de los docentes. Desde una definición que se puede llamar "universal”, en el modelo de evaluación el eje Academia es el que " alude a las condiciones fundamentales para el ejercicio de la docencia universitaria de calidad, tomando en cuenta que la docencia universitaria debe constituirse en una verdadera comunidad científica, profesional o artística con autoridad, reconocimiento, legitimidad, dedicación y debida protección en su medio". Uno de los puntos claves del eje Academia es la situación de los docentes ya que “... la calidad de la enseñanza impartida en las instituciones de educación superior está relacionada con la formación 
académica de sus docentes, su dedicación, su institucionalización, los derechos de los docentes y condiciones de vinculación con la universidad". (CEAACES, Informe Final, p 10, 2013).

En este ámbito, los resultados fueron catastróficos: en el período de evaluación ningún facilitador entró a la UINPI siguiendo una normativa propia; ningún facilitador recibió auspicio para actualización; ninguna facilitadora ocupó algún puesto de dirección; ningún facilitador fue ascendido, ni estuvo en la categoría máxima institucional durante el período evaluado; la sumatoria de la remuneración promedio de los facilitadores a tiempo completo era cero, mientras la sumatoria de la remuneración promedio por hora de los facilitadores a tiempo parcial era de 4,63,97 dólares, de un total de 56 facilitadores a tiempo parcial; la sumatoria del número de horas de clases mensual de 60 minutos dictada por profesores a tiempo completo era o. Además, ningún facilitador contaba con título de Ph.D. ni estaba estudiando para conseguirlo, ninguno estaba cursando una maestría y de 48 facilitadores, 46 no tenían título de maestría ni de doctorado. En el mismo período, un total de 24 facilitadores habían sido de pueblos y nacionalidades, 55 tenían formación en pueblos y nacionalidades, habían 17 facilitadores Quichua o Shuar hablantes y un total de 6 facilitadores eran intelectuales comunitarios.

Como veremos, la UINPI elaboró una conceptualización de la pedagogía desde una oposición binaria entre lo que definía como una pedagogía occidental decadente y utilitarista en contraste con su propio modelo, lo que generó un escenario que imposibilitaba la conformación de una planta de profesores con las mínimas condiciones para responder a los requerimientos de formación universitaria. En noviembre del 2005 el centro Ushay Yachay o de la Interculturalidad de la UINPI diseñó el documento "Proceso de Selección y evaluación de Docentes" donde establece una serie de criterios idiosincráticos a través de los cuales se conformaría la planta docente. La parte correspondiente al proceso de selección de profesores expresa una perspectiva maniquea en la que el modelo universitario "convencional" (supuestamente defendido por el estado nacional) encarna la sumisión, el instrumentalismo, la pasividad, el control y la manipulación. Así, en el modelo basado en "los paradigmas occidentales", en los que el profesor es un "iluminado" y los estudiantes un colectivo menospreciado, se sostiene:

"Algunos aspectos que se aprende en la vida universitaria convencional. A que mientras más horas se pasa en ella más vale uno en el mercado. A valorar el consumo siempre insatisfecho. A valorar la promoción jerárquica, la sumisión y pasividad. A tener ganadores y perdedores. A convertirnos en insatisfechos o frustrados. A ser especialista o súper especialistas. A reflexionarnos y pensarnos como seres fragmento. A aceptar sin revelarse (sic) "su" lugar en la sociedad. A callar y aceptar resignadamente. A renunciar a la soberanía. A controlar y manipular. A no ser nosotros mismos. A ser resentidos sociales o acumuladores 
insaciables. A creer que ser es tener". (Amawtay Wasi, proceso de selección y evaluación de docentes, noviembre 2005, sp)

Frente a la pedagogía "Occidental", la UINPI se define como "impulsora de un proceso alternativo propio de la educación superior" a partir del cual define los facilitadores que requiere. De estos profesores se espera "que rompan con los paradigmas occidentales", a partir de su inmersión en un modelo tan radicalmente alternativo como inasible:

Algunos aspectos qué (sic) queremos de la vida universitaria bajo un sistema alternativo. Que sea convinencial (sic), para aprender conviviendo convivencialmente. Que nos permita aprender a re-aprender sintiéndonos tierra. Que nos permita comprender la condición humana. Que sea parte de la constelación pensante, del cosmos vivo. Que revalorice la vida austera; la austeridad como valor individual y social. Que sea un ambiente de ambientes derrochador de alegría. Que este (sic) orientada a la sabiduría y al "buen vivir", al logro de la vida plena. Que dispute el sentido de la vida en todos los aspectos que la implica. Que este (sic) profundamente articulada a las diversas culturas. Que se fundamente en el respeto a la otredad, a lo diferente, a lo diverso. Que fomente el diálogo, las conversaciones, el lenguajeo. (Amawtay Wasi, proceso de selección y evaluación de docentes, noviembre 2005).

Sobre esta base se estableció un procedimiento de selección de los facilitadores y un perfil general que se reflejaba en unos puntajes determinados en una tabla:

\begin{tabular}{|l|l|c|}
\hline No & \multicolumn{1}{|c|}{ Consideración } & $\begin{array}{c}\text { Puntaje } \\
\text { Estimado }\end{array}$ \\
\hline 1 & Pertenecer una organización social de base, especialmente ligado al movimiento indígena. & 10 \\
\hline 2 & Haber participado en el proceso de constitución de la UINPI. & 10 \\
\hline 3 & Pertenecer a un pueblo o nacionalidad indígena o afroecuatoriano. & 10 \\
\hline 4 & Sabio o Yachac con amplio conocimiento y experiencia en el tema requerido. & 10 \\
\hline 5 & Título de tercer nivel. & 10 \\
\hline 6 & Título de cuarto nivel. & 10 \\
\hline 7 & $\begin{array}{l}\text { Haber participado en espacios de capacitación y profesionalización promocionados por la UINPI, } \\
\text { como: } \\
\text { Diplomado en Investigación Intercultural, Maestría en Derechos Humanos y Pueblo Indígenas } \\
\text { yotros. }\end{array}$ & 20 \\
\hline 8 & $\begin{array}{l}\text { Experiencia y solvencia profesional ligada a procesos de } \\
\text { emprendimientos comunitarios y/o empresariales. }\end{array}$ & 20 \\
\hline 9 & total & 100 \\
\hline
\end{tabular}

A través de un procedimiento que no fue cumplido e incluía la presentación de perfiles por parte de los centros de saber, la difusión de los perfiles a las instituciones patrocinadoras, el análisis de las carpetas por el coordinador de los centros, la aprobación del requerimiento por el consejo directivo, la UINPI 
estableció un cuadro en el que la sumatoria de la valoración de los títulos apenas alcanzaba al $20 \%$ de criterios idiosincráticos que no tenían nada que ver con la trayectoria académica, investigativa o de gestión educativa de los postulantes.

En otros ámbitos, los resultados de la evaluación tampoco fueron optimistas. En el campo del criterio institucional, que evalúa temas como la organización y gestión administrativa, las políticas de funcionamiento y su transparencia, se reconoció como eje intercultural la participación de la comunidad. Lo que más resalta en este ámbito es que el patrimonio declarado de la UINPI era o.

Bajo la categoría de soporte pedagógico, en el que entran componentes universales como espacios de aprendizaje -aulas, bibliotecas y oficinas para docentes-, se dio especial importancia a la existencia de un acervo bibliográfico que contuviera títulos de pueblos y nacionalidades. En este caso, la UINPI contaba sólo con 8 aulas funcionales y no tenía una sola oficina para profesores a tiempo completo.

Enlacategoríaámbitosdeaprendizajequeincluyecriterioseindicadorescomo currículos, emprendimientos o investigaciones se tomaron en consideración las formas específicas de difusión de los conocimientos y saberes existentes en la universidad en estrecha relación con los pueblos y nacionalidades, además de los conocimientos científicos que se anclan en convencionalismos más universales. También se reconoció y valoró la relación de la investigación con la comunidad. En este caso, la evaluación arrojó o publicaciones en revistas indexadas, o libros publicados revisados por pares, 1 investigación financiada en el período de evaluación, 1 convenio ejecutado con fines de investigación, un presupuesto de 6.000 dólares dedicado a investigación, mientras en el mismo tiempo ejecutó un presupuesto de 146.078,49 dólares en el campo administrativo. En términos cualitativos la evaluación arrojó como resultados un cumplimiento deficiente en cogobierno, en transparencia, en participación de la comunidad, en registro de uso de bibliotecas, así como un cumplimiento parcial en mesocurrículo, accesibilidad, y seguimiento a graduados.

El segundo componente de la evaluación implementada a la UINPI fue el Examen de evaluación de resultados de Aprendizaje que contemplaba resultados de Aprendizajes Genéricos y Resultados de Aprendizajes en Lenguas Originarios. El examen de evaluación de la UINPI fue un instrumento construido, validado y contextualizado en la realidad de la Universidad y los reactivos (preguntas, problemas, situaciones y/o afirmaciones) fueron producidos luego del análisis y de la identificación de las competencias formativas básicas que debían tener los profesionales de nivel superior. Los exámenes también fueron diseñados de acuerdo a las carreras y conocimientos oficialmente enseñados por la Universidad.

En el caso del conocimiento del quichua, en el Libro Verde (Aprender en la Sabiduría y el Buen Vivir) considerado por los artífices de la UINPI como la más elaborada síntesis de la propuesta educativa, respecto al idioma nativo se dice: "al ser el kichwa, el idioma oficial de la Amawtay Wasi, se propone que los estudiantes desde un inicio sepan que para poder pasar al tercer semestre de 
la carrera deben tener aprobados al menos tres niveles de kichwa y para pasar al séptimo semestre deben aprobarlo en su totalidad. En el caso del segundo idioma, será una opción personal y un requisito para la carrera; para pasar al noveno nivel de la carrera deben tener aprobados la mitad de niveles requeridos para aprenderlo y para graduarse (décimo nivel) aprobar completamente el segundo idioma. (Amawtay Wasi, 2004: 216)

Sin embargo, el día 2 de octubre del 2013 por petición del rector de la UINPI, se firmó un acuerdo con el presidente del CEAACES en el que se establece que "Los representantes de la Universidad Intercultural de las Nacionalidades y Pueblos Indígenas "Amawtay Wasi", han indicado que el uso de las lenguas ancestrales por parte de los estudiantes es incipiente, pese a los esfuerzos realizados por la institución, para recuperar y mantener dichas lenguas, debido a la realidad de minorización de esas lenguas en el país. En este sentido, solicitan que el Consejo considere que el examen de resultados de aprendizaje no se realice en lenguas kichwa y shuar, sino únicamente en castellano" (Acuerdo octubre 2 de 2013 CEAACES-UINPI).

A pesar de que el organismo evaluador aceptó la argumentación del rector de la UINPI en la ajaa de Chiguaza, una vez los estudiantes fueron notificados del acuerdo por parte de los miembros del CEAACES, el coordinador de la sede se mostró desconcertado y expresó su preocupación porque los estudiantes habían esperado presentar el examen en Shuar Chicham como lenguaje mayoritario en la Ajaa, y contrariando la decisión de las autoridades tomaron el examen de manera bilingüe. En este contexto pueden entenderse los resultados generales de esta segunda evaluación que fueron del total de $26,9 \%$, distribuidos así: entorno de aprendizaje (academia, infraestructura, etc.) equivalente a 22,8/100 y los resultados de aprendizaje (exámenes) 31/10o. Con estos antecedentes y estos resultados fue que el CEAACES tomó la decisión de desaprobar la UINPI.

\section{Amawtay Wasi, intelectuales metropolitanos y neoliberalismo.}

Un grupo de intelectuales metropolitanos ha producido un conjunto de ensayos e investigaciones sobre la UINPI. Algunos de estos estudios, se han enfocado en la universidad como proyecto (Walsh, 2007; Mignolo, 2003), antes incluso de que estuviera en ejecución y establecen una desmesura cultural que les hace calificar a la UINPI como la alternativa a la decadente universidad occidental (Figueroa, 2015 ). Luego de la evaluación y la salida de la UINPI del sistema de educación, se han escrito algunas tesis de maestría en instituciones como la Flacso y la Universidad Andina y se encuentran accesibles estudios como los de Daniel Mato (2014), Krainer et al (2017) y Martínez Novo (2016; 2020) que tienen como carácter común criticar el proceso de evaluación de la Uinpi anteponiendo las categorías de estado y pueblos y nacionalidades. En el caso de Krainer, avala la decisión inicial de los directivos de la UINPI de crear una 
institución fuera del sistema regular. Como veremos en detalle, en ninguna de estas investigaciones se muestra que se haya hecho una visita a la UINPI durante su funcionamiento ni tampoco se muestra ninguna aproximación empírica a toda la documentación relacionada con el proceso evaluativo. Como quisiera mostrar, los enfoques y conclusiones de estos trabajos arrojan una serie de interrogantes sobre las retóricas intelectuales en torno a la educación intercultural, sobre la articulación del multiculturalismo con el neoliberalismo y sobre los límites del culturalismo neoliberal frente al desafío de construir una sociedad intercultural que disminuya la desigualdad económica y social.

Martínez Novo (2016, 2020), citando a Hale (2005) inserta su análisis de evaluación de la UINPI dentro de la Educación Intercultural Bilingüe como caso paradigmático de multiculturalismo neoliberal, en el cual las organizaciones manejan la educación sin acceso a recursos suficientes. Sin embargo, más adelante también plantea que el origen de la Educación Intercultural bilingüe “... cuestiona el colonialismo y la asimilación forzada de los pueblos indígenas y busca tanto la preservación y fortalecimiento de las lenguas y culturas indígenas como el acceso de los pueblos indígenas a la educación" (Cortina 2014; Martínez Novo, 2004). Al asociar neoliberalismo con falta de recursos económicos Martínez deja de lado el hecho medular de que durante el régimen de Correa no sólo hubo una acción reguladora por parte del estado a un sistema educativo profundamente afectado por el neoliberalismo sino que esta intervención vino acompañada de una clara definición legal de los compromisos y obligaciones económicas del estado respecto al sistema educativo. La inyección económica del régimen a la educación se tradujo en una inversión que pasó de un poco más del 1\% del PIB antes de las reformas implementadas durante el período de Correa a una inversión sostenida que alcanzó a superar el $5 \%$ del PIB al final del gobierno. Esta inversión respaldada de instrumentos legales pos neoliberales fue un intento de romper las profundas asimetrías que había en un país en el cual un minúsculo grupo de universidades, ubicadas en Quito, con capital internacional y en su mayoría dedicadas al postgrado, alcanzaba la categoría de excelencia, mientras las inmensa mayoría funcionaban con los parámetros del caos neoliberal.

De igual manera, como puede colegirse del mismo Hale, el neoliberalismo no apunta a una asimilación forzada, sino a una asimilación diferenciada en la cual el estado acepta todo culturalismo siempre que éste no cuestione las asimetrías estructurales. En estricto rigor, la noción de asimilación forzada es una categoría que le permite a Martínez Novo ratificar una perspectiva teórica y política neorelativista funcional al neoliberalismo. Mediante el criterio de asimilación forzada Martínez coloca al estado nacional y a los pueblos y nacionalidades en dos lugares antagónicos y estructuralmente diferenciados, lo que le sirve además para racionalizar su crítica a la función reguladora del estado que se dio en el campo de la educación durante el correismo. El desconocimiento del proceso de evaluación por parte de Martínez Novo le lleva a sostener que a la Amawtay 
Wasi se le evaluó con los mismos estándares que a la Universidad San Francisco, sede de la élite nacional y “... se le trató como a cualquier otra universidad y se le evaluó en términos del número de profesores con $\mathrm{PhD}$, del número de profesores a tiempo completo, de su infraestructura, del número de volúmenes en la biblioteca, e incluso de su cafetería y parqueaderos", argumento que no se sostiene al revisar, como ya vimos, un modelo que tomó entre las premisas fundamentales los derechos interculturales, el aseguramiento de la calidad y la responsabilidad social de la educación.

En el caso de Daniel Mato y Anita krainer también ratifican la oposición radical entre estado nación y pueblos y nacionalidades usando el neorelativismo posmoderno. Estas perspectivas coinciden con las de Mignolo (2003) y Walsh (2007), quienes elaboran argumentos culturalistas basados en un neorelativismo radical que ratifica una mirada dualista entre "Occidente" y los pueblos y nacionalidades. Según Mignolo, antes de que empezara siquiera a funcionar, la UINPI era una alternativa a las pretensiones de universalidad del conocimiento occidental que es válido solo para Europa y los Estados Unidos, a la vez que mostraba el fracaso de las universidades latinoamericanas manejadas por unas elites criollas que sólo buscan parecerse a las elites europeas y norteamericanas (Mignolo, 2003), mientras para Walsh, citando a Reinaga, el mérito de la Amawtay Wasi era el de romper con las herencias coloniales y materializar las aspiraciones de crear un nativismo indígena que no tuviera en cuenta "ni a Marx ni a Cristo" y reivindicaba la lucha de los indígenas por que viene de "... muy lejos, desde el mismo momento en el que las hordas españolas invadieron la confederación de pueblos indo americanos" y se enfoca "contra todo los vestigios europeos... la ley romana, el código napoleónico, la democracia francesa, el marxismo- leninismo, todo lo que nos mantiene en dependencia, en colonialismo, en la obscuridad sin permitirnos encontrar la luz" (Reinaga 1970/2001, p. 15, en Walsh).

Partiendo de un pacto intelectual con los proponentes del proyecto, Walsh sostiene que la UINPI creó una interculturalidad que rompe con Occidente porque parte de "... la cosmología y la filosofía de Abya Yala" y en una especie de justificación teórica de la autarquía desde la interculturalidad, sostiene que la universidad constituye una ruptura epistemológica porque crea

...una noción de autonomía entendida como libertad de control de las iglesias, de los hacendados, de los comerciantes intermediarios y de los partidos políticos -incluidos los de la izquierda- así como de las instituciones y de los modelos dominantes del estado y también como la concreción de proyectos políticos que se materializan en lo social, lo político, lo económico y lo político. (Walsh, 2007, 30-31)

Estas perspectivas posmodernas radicales, se convierten en razonamientos antropológicos que presuponen que los pueblos y nacionalidades están por fuera de la lógica de la modernidad, por fuera del tiempo y del espacio del 
estado nacional y de la nación. El caso de la Amawtay Wasi nos muestra que si bien estas teorías pueden constituir una alternativa intelectual y estética para paliar los desasosiegos de la modernidad en quienes las formulan, en rigor, su cercanía con el neoliberalismo favorece la profundización de las asimetrías de pueblos y nacionalidades ya que se oponen a toda regularización que se haga de la educación intercultural bilingüe y de la autarquía que caracteriza al sistema en el contexto neoliberal. Sin embargo, la propia historia de la educación intercultural bilingüe revela la existencia de voces alternativas en pueblos y nacionalidades que les permite reconocerlos como actores del presente histórico y como constructores del estado nacional. Estas voces, que denominaré voces republicanas permiten pensar en un modelo de educación intercultural en el que coexistan los derechos de los pueblos y nacionalidades y el cumplimiento de la responsabilidad social de la educación como estrategia que permite acortar las brechas de la desigualdad que se han profundizado en el contexto del auge neoliberal. Al mirar la historia del instituto Quilloac de la provincia del Cañar, podremos ver las tensiones derivadas entre el culturalismo neoliberal y los reclamos republicanos que formulan líderes e intelectuales indígenas vinculados a la educación intercultural.

\section{Currículo intercultural, republicanismo y neoliberalismo: el caso de Quilloac.}

En las últimas décadas, especialmente en el campo de la historia social y de la filosofía política, se han venido consolidando una serie de perspectivas analíticas que de manera explícita reconocen el papel activo que los sectores subalternizados por razones raciales, económicas o de género han cumplido en la construcción de los estados nacionales. A diferencia de los teóricos posmodernos que consideran que los sectores populares subalternizados, indios, negros, montubios, están insertos dentro de unos paradigmas culturales provenientes de tradiciones ancestrales que los diferencia de manera radical de los estados nacionales (Walsh, 2007; Mignolo, 2003), estudios clásicos como los de C.L.R James (1989) o estudios contemporáneos como los de Sheller (2012), Scott, (2000), Sanders (2009), Coronel (2018), Figueroa (2009), y en el campo de la filosofía política trabajos como los de Coronel y Cadahia (2018) y Guanche (2018), proponen nuevas lecturas de los archivos y de las tradiciones que hacen visibles los discursos y las prácticas políticas y culturales impulsadas por los sectores populares en la construcción de proyectos sociopolíticos que garanticen una participación amplia y democrática y un disfrute de las promesas emancipatorias de la modernidad.

Mientras varios de los estudios sobre republicanismo se han enfocado en el papel del radicalismo popular en coyunturas claves de la historia política como la independencia, la emancipación o las luchas del liberalismo, en este acápite, a través de la historia situada del Instituto Intercultural Bilingüe Quilloac, 
del Cañar, quiero mostrar como la construcción de los proyectos pedagógicos interculturales están marcados por discursos y prácticas republicanas que matizan las tendencias neoliberales de la educación intercultural bilingüe. Dentro de las contribuciones que encuentro más relevantes de la historia del instituto y que convergen con las tradiciones republicanas están las exigencias políticas de los cañaris que van desde la lucha por el acceso a la alfabetización para romper los dispositivos primarios de dominación hacendataria, hasta el diseño de un proyecto institucional que incluye elementos que satisfacen tanto las demandas y requerimientos del estado nacional como las específicamente locales e idiosincráticas; la historia situada del instituto Quilloac también muestra que las luchas políticas de los sectores subalternizados no se limita a la defensa a ultranza de lo que los intelectuales -metropolitanos o localesdefinen como la cultura ancestral, sino que incluyen dispositivos y tecnologías educativas actuales y modernas que permiten responder a las demandas del presente; finalmente, la historia de Quilloac muestra cómo el republicanismo popular saca la educación intercultural del plano de simple defensa de las particularidades culturales y la lleva a la disputa por la construcción de una hegemonía democrático radical, que aspira al ejercicio de los derechos individuales y colectivos, en los ámbitos nacional, regional y local, tanto en el estado como en la sociedad.

La etnoeducación en Ecuador está directamente vinculada a la historia política de los pueblos indígenas desde los años 40 cuando tres figuras proteicas, las indígenas Dolores Cacuango y Tránsito Amaguaña, junto a la mestiza Luisa Gómez de la Torres, incluyeron a las demandas políticas impulsadas por el partido comunista, el derecho al acceso a una educación pertinente para los indígenas. En estos casi 80 años de un reclamo explícito de temáticas pertinentes para los grupos indígenas, la etnoeducación ha estado atravesada por la tensión entre agendas políticas que colocan mayor énfasis en reclamos culturales específicos de los pueblos indígenas privilegiando las diferencias con respecto al estado nacional, mientras otras propenden por una mayor articulación entre los requerimientos locales específicos de los pueblos y nacionalidades y las necesidades nacionales. La historia de la etnoeducación refleja también la existencia de tensiones entre quienes proponen trabajar de manera conjunta con diferentes movimientos y con la izquierda, mientras otros sectores paradójicamente reclaman autonomía política, al tiempo que tienen una profunda articulación con sectores como las iglesias, las universidades e intelectuales nacionales e internacionales que son claves en la construcción de propuestas etnoeducativas y discursos autonomistas.

En el Ecuador, las primeras experiencias en las cuales se hizo explícita la necesidad de reconocimiento de las realidades indígenas en la educación ocurrió entre los años 1945 y 1960, en las escuelas que surgieron con el impulso de Dolores Cacuango en Cayambe. Estas escuelas, que luego estarían bajo la dirección de las Misioneras Lauritas, extendieron esta práctica a Imbabura 
(Conejo Arellano, 2008), mientras estaban los salesianos, quienes trabajaron con los Shuar. En las décadas de 1960 y 1970, hubo esporádicos trabajos, pero entre los años 1978 y 1984, se creó el Centro de Investigaciones para la Educación Indígena -CIEI, institución que sería clave en la formación de las organizaciones indígenas ulteriores ya que los miembros del CIEI entre los años 1979 y 1980 fundaron el Consejo Nacional de Coordinación de las Nacionalidades Indígenas (CONACNIE), que devendría en la Confederación de Nacionalidades Indígenas del Ecuador (CONAIE). Mientras, a principios de los años 8o's, el Estado reconoció la existencia de programas de educación en lenguas vernáculas y en 1987, apareció el Primer Programa Intercultural de Auto Enseñanza en Quichua en Secundaria (Yánez Cossio, 1994).

Otras experiencias que contribuyeron a impulsar la educación bilingüe fueron el Instituto Lingüístico de Verano, que se dedicó principalmente a la traducción de la Biblia y operó en el país entre los años 1952 y 1981; la Misión Andina, que llevó a cabo la elaboración de cartillas en quichua sobre mitologías y creencias indígenas; las Escuelas Radiofónicas Populares, regidas por Monseñor "Leonidas Proaño", dirigidas a alfabetizar en quichua y el Sistema Radiofónico Shuar, que empezó a operar en el año 1972.

El año de 1979, se oficializó el Sistema de Educación Bilingüe Bicultural Radiofónica Shuar. También existieron las Escuelas Indígenas de Simiatug, el Sistema de Escuelas Indígenas de Cotopaxi, en el que se educa principalmente en quichua, las Escuelas Bilingües de la Federación de Comunas "Unión de Nativos de la Amazonia FCNUAE, el Programa de Alfabetización Quichua, "Chimborazo Caipimi”, que era un proyecto exclusivo para el Chimborazo, el Colegio Nacional Macac, que forma parte de la Fundación Macac.

También funciona el Proyecto Alternativo de Educación Bilingüe, en las provincias de Napo y Pastaza y han existido una serie de convenios entre la Confederación de Nacionalidades Indígenas del Ecuador, con instancias gubernamentales como el antiguo Ministerio de Educación y Cultura (Conejo Arellano, 2008). Todo este proceso permitió que en 1988 se creara la Dirección Indígena de Educación Intercultural Bilingüe, así como las Direcciones Provinciales de Educación Intercultural Bilingüe. En 1992 se aprobó el carácter descentralizado de la DINEIB y al año siguiente se oficializó el modelo de Educación Intercultural Bilingüe (Vélez, 2008).

La historia del instituto intercultural Quilloac está estrechamente relacionada con las luchas de los campesinos contra la hacienda Guantug, que había fundamentado su consetudinario poder en estructuras racistas y precarias. La historia también va ligada al aparecimiento y la consolidación de Organizaciones políticas indígenas de carácter nacional como la CONAIE, y organizaciones de segundo grado de carácter más local. La fundación del Instituto en 1981 materializó un anhelo de los comuneros construido en la lucha política contra el analfabetismo deliberado creado por la hacienda. Quiero enfocarme en la biografía intelectual del dirigente José Antonio Quinde 
porque sintetiza varios de los procesos que van desde la lucha contra el poder hacendatario hasta la fundación del instituto.

Quinde fue rector del Instituto Quilloac por 22 años y ha sido uno de los protagonistas más relevantes de la historia del movimiento indígena y de la educación intercultural a nivel local, regional y nacional. Fue fundador de la Organización Provincial de Cañar en 1970 y primer presidente de la ECUARUNARI a nivel nacional en 1972. Nació y pasó su infancia temprana en las comunidades libres de la zona pero al morir su padre se vio forzado a mantener a sus hermanos y tuvo que vincularse a la hacienda Guanto, donde experimentó la sobre explotación, la exclusión y el racismo que caracterizaron las relaciones interétnicas del Austro ecuatoriano y que fueron tan vívidamente descritas por el antropólogo Hugo Burgos en su estudio sobre las relaciones interétnicas en Riobamba.

En las primeras décadas del siglo XX la hacienda Guántug era propiedad de Florencia Astudillo, heredera de mayorazgos, devota ferviente, solterona, recordada aun como una matrona que obligaba a los indígenas a que la llevaran en andas; al morir en 1956 dejó en herencia la hacienda al asilo de Ancianos Desamparados de Cristo Rey.

De acuerdo a la información de Torres (2009), la donación de Guántug al asilo ocurrió en 1935, pero Astudillo mantuvo el control sobre la hacienda mediante administradores y mayorales y guardó “... para sí el uso de las casas de habitación de las distintas propiedades que habían sido donadas y también parecería ser que los réditos de la producción" (Torres: 2009, 143). La hacienda tenía cerca de 30.000 hectáreas basada en la explotación extensiva y además de la absorbente presencia de la propietaria, tenía un bajo nivel de especialización y de producción. Antonio Quinde evoca los tiempos de la hacienda como una época en la que los comuneros estaban totalmente enclaustrados en un sistema que buscaba evitar cualquier vínculo de los trabajadores con el exterior. Así, en los días de trabajo extra los miembros de la familia huasipunguera tenían que dedicarse también a producir los vestidos para cubrir las necesidades básicas.

En Guantug, los castigos eran cotidianos: los vejámenes de los propietarios y administradores incluían la sobreexplotación de la fuerza laboral, el incumplimiento de las obligaciones económicas de cualquier tipo, la obligación de los trabajadores a responder a demandas laborales de la hacienda sin importar que los días estuvieran asignados a sus propias parcelas, además de permanentes castigos físicos y humillaciones, que inducían al acatamiento de la autoridad, al silencio y a los trabajadores se les negaba de manera deliberada el acceso a cualquier forma de educación. Como lo evoca Quinde, durante las extenuantes jornadas laborales “... nadie podía decir ni media palabra, nada podía salir de la boca, ni un sonido de palabra, todos trabajábamos como mudos, así era el sacrificio de los pueblos". La vigilancia de los mayorales se complementaba con la labor de la iglesia que 
... con sus curas, sus monjas, lo único que enseñaban era a rezar, enseñaban a trabajar, decían entonces que hay que rezar a Dios y hay que obedecer al patrón, de ahí a nosotros no nos enseñó ni a leer ni a escribir, absolutamente nada.

La situación empezó a cambiar con los aires reformistas de mediados de los sesenta cuando la revolución cubana, las movilizaciones indígenas y campesinas que buscaban eliminar las formas precaristas de producción agraria y el papel activo de terratenientes en introducir innovaciones tecnológicas para aumentar la productividad de sus tierras, motivaron las reformas agrarias. También fue clave la Teología de la Liberación que construyó una agenda de apoyo a la reforma agraria y a la construcción de proyectos educativos favorables a los indígenas y campesinos. Quinde fue protagonista de la organización de los indígenas a favor de la reforma y cuando ésta se decreta en 1964, la hacienda estaba a manos del administrador Enrique Toral Arízaga, representante del Asilo de Cristo Rey, quien la vendió al IERAC como requisito previo a la compra definitiva de los predios de parte de los comuneros en 1968. Todo este proceso permitió que el 27 de noviembre de ese año, 10 cooperativas que habían logrado conformarse ocuparan temporalmente las 30 mil hectáreas que habían estado a manos del asilo de las monjas del Sagrado Corazón. En la segunda oleada de reforma agraria impulsada en el gobierno de Rodríguez Lara se crea el 8 de enero de 1970 la Unión Provincial de Cooperativas y Comunas del Cañar-UPCCC- que jugaría un papel estratégico en las luchas subsiguientes.

De acuerdo a Quinde, en medio del conflicto con la hacienda, los campesinos indígenas constataron la inaplazable necesidad de crear un instituto de educación. Confrontados a la necesidad de gestionar los trámites para poder comprar las tierras del antiguo latifundio evidenciaron las falencias en la educación formal y política de los comuneros quienes no podían ni siquiera firmar un acta de las reuniones que hacían. Pudieron constatar que ninguno de ellos había terminado ni siquiera la primaria al pasar toda una vida encerrados en una hacienda en la que les prohibían acceder a cualquier forma de educación y donde, en expresión de Antonio Quinde, “..sólo les habían enseñado a temer a Dios y a obedecer al patrón".

En rigor, la memoria registra no sólo que la hacienda había creado un sistema excluyente para los campesinos indígenas sino que la educación se había convertido en un privilegio de los blanco mestizos, a pesar de las iniciativas impulsadas por organismos internacionales como la Misión Andina o las órdenes religiosas como los esculapios.

La primera unidad educativa, la Escuela Rumiñahui, fue fundada en la década de los cuarenta, pero los indígenas estaban excluidos de ella. En 1964, en medio de la fragmentación de la hacienda y de las luchas indígenas, en Asambleas en Quilloac aparecieron las primeras iniciativas para crear un colegio indígena, al tiempo que a la orden de los esculapios se les entregaron 11 hectáreas destinadas a crear un colegio agronómico que condujo a la fundación 
del colegio Calazans en 1972. Varios comuneros de Quilloac recuerdan con indignación que el colegio agronómico había sido concebido inicialmente para los indígenas pero mediante presiones los mestizos terminaron apropiándose del colegio, a la vez que aprovecharon de la condición de precariedad formativa que padecían los indígenas. Algunos lograron entrar a la escuela en los años 70, y la pelea por la educación se convirtió en una de las principales agendas de la movilización indígena. Los contactos institucionales que se fortalecieron desde la década de los setenta permitieron que las experiencias de lucha locales por la educación se difundieran y sirvieran de ejemplo para otras comunidades. Aprovechando los aires reformistas del gobierno de Jaime Roldós consiguieron la creación del Instituto Quilloac el año de 1981. A la inauguración del instituto llegó el propio presidente Roldós y el ministro de Educación lo que satisfacía el anhelo expresado por Antonio Quinde y por varios dirigentes de conseguir un "cambio intelectual" que merecían como seres humanos y seguir combatiendo las herencias racistas y coloniales que recibieron de la hacienda. Constatando de nuevo que no contaban con el personal formado, los dirigentes llamaron a Antonio Quinde, personaje clave en la implementación del sistema educativo reclamado por los indígenas.

Antonio Quinde, como comunero libre, había empezado su educación a los 9 años en la Escuela Rumiñahui pero a la muerte de su padre debió abandonar sus estudios. Su experiencia en la escuela fue terrible ya que estaba marcada por el racismo y la exclusión: los maestros les exigían cortarse el cabello, les prohibían estrictamente el uso del poncho y del sombrero, establecieron una vigilancia punitiva y en caso de que encontraran pretextos como que los niños tuvieran rastros de tierra en las uñas, hablaran quichua o se retrasaran un minuto, les propinaban castigos físicos brutales. La primera alternativa que encontró Quinde fue la militancia organizativa y pudo autoeducarse; leía incluso papeles y recortes sueltos que encontraba por el suelo. Así ingresó al instituto a la edad de 37años, y también tuvo problemas en un inicio cuando los mestizos tenían el poder y ejercían el racismo pero fueron directamente confrontados por Antonio quien ya contaba con un importante bagaje de militancia a favor de los derechos indígenas. Terminado el Instituto se matriculó en derecho en la Universidad de Cuenca, decidido a continuar su formación para la defensa de los indígenas, pero mientras estaba estudiando recibió en 1987 una comisión que le propuso el rectorado del Instituto Quilloac.

Antonio en un principio estaba temeroso del cargo pero tuvo el apoyo decidido de varios de sus compañeros indígenas y de un importante grupo de mestizos profesores y colaboradores del instituto, lo que le permitió superar la animadversión de los que no concebían que la dirección del instituto estuviera a manos de un indígena. La experiencia organizativa, su voluntad en entrenarse en el manejo de la cosa pública y el reconocimiento de su liderazgo en las luchas políticas fue el principal capital con el que contó frente a desafíos como el de garantizar una educación de calidad que fuera pertinente para los indígenas de 
Quilloac. Otra experiencia fundamental para su formación fue su trayectoria en el proyecto de Ñucanchic Huasi. Esta organización estuvo ubicada en los terrenos del antiguo hospital San Clemente que fueron entregados en comodato a la UPCCC en la década de los ochenta. Allí funcionaron talleres de mecánica industrial y carpintería, tiendas, hospedaje para estudiantes indígenas, así como espacios para cursos de capacitación, hasta el año de 1994, cuando la casa fue quemada en uno de los mas brutales actos de racismo en la historia reciente de Cañar (Muyulema, 1997: 21). En Ñucanchi Huasi, Antonio Quinde hizo un importante trabajo que fue reconocido para la validación de su función como rector del instituto.

Consciente de las grandes deficiencias en la formación en Quichua, Quinde dedicó parte de sus esfuerzos a la formación del sistema intercultural bilingüe y a crear un área de quichua como asunto estratégico para su comunidad. Simultáneamente, lograron convertir a la escuela Rumiñahui en una institución bilingüe y mediante un trabajo conjunto con la comunidad, Quinde ha combatido el escepticismo de los mayores heredado de la dominación hacendataria. Para él y para varios comuneros el instituto tendría un impacto cultural transformador porque permitiría que los indígenas valoraran elementos despreciados por la hacienda, como la lengua, la comida, la vivienda, la ropa, los sistemas de cultivo, y serviría para el empoderamiento de los indígenas en su lucha contra el racismo y la discriminación.

Para Quinde, la educación intercultural permitiría incluso cuestionar la distribución del acceso a los campos de conocimiento de acuerdo a la pertenencia étnica. Para él es urgente romper la división del trabajo en la que los indígenas están dedicados exclusivamente al campo de la cultura, mientras los mestizos dominan los campos de otras profesiones. Para romper ese modo de dominación propone un movimiento estratégico, que incluye perfeccionar el dominio del quichua y ampliarlo al conjunto de la sociedad porque, en sus palabras, la división lingüística también es una división de poder: “... hemos ido viendo de que en muchos de los casos por el hecho de que los hispano hablantes no conocen el quichua, los profesionales quichuas como que nos hemos encargados más en las áreas culturales, las áreas lingüísticas, en eso últimamente hemos analizado, hemos reaccionado, hemos dicho nosotros por qué tenemos que estar más bien dando la posibilidad de que los hispanos estén con las áreas de especialidad como matemáticas, físicas, biología y nosotros solamente arrinconándonos a lo que es el quichua, a lo que es a los temas culturales, pero eso no quiere decir que nosotros no queremos saber de eso, sino más bien, también hay que ir empoderando, ganando espacio, porque en mucho de los casos que queremos ubicar en las partidas áreas como son matemáticas, física no hay nuestro personal indígena... hemos visto que es muy pertinente de que nuestra gente si debe ir empoderando esas materiales de especialidad, las materias técnicas" (Quinde). 
Quinde reconoce que la interculturalidad no es un tema indígena sino que es una operación política que involucra a toda la sociedad. Demanda que los indígenas hagan una utilización clara de elementos como la planificación curricular o la formación permanente de los profesionales indígenas mediante una capacitación pertinente. Al tiempo que urge a las comunidades a que creen condiciones para la recepción de la mano de obra indígena profesional en el nivel local. Las propuestas de Quinde llegan incluso a concebir que el instituto Quilloac permita la creación de un instituto de estudios avanzados que solidifique la agenda regional de los intelectuales indígenas que ha cubierto temas que va desde la arqueología, la pedagogía, el idioma quichua, hasta las ciencias experimentales, las matemáticas y las ciencias, entendidas como etnoconocimientos y como conocimientos universales. Inserta en las luchas políticas contra el analfabetismo y la marginación del conocimiento propiciada por la hacienda, propuestas de intelectuales indígenas como José Antonio Quinde colocan las demandas educativas de los indígenas en el presente global, involucran los espacios locales a la vez que los trascienden e interpelan al conjunto de los sectores marginales y de la sociedad en su conjunto desde la imaginación de una interculturalidad que transforme al conjunto de la sociedad. Intelectuales como Quinde, colocan en la escena de la educación intercultural una serie de legados republicanos que, a diferencia de los intelectuales posmodernos, disputan la hegemonía neoliberal y llaman a profundizar una democracia radical intercultural.

\section{Documentos de evaluación}

Amawtay Wasi, proceso de selección y evaluación de docentes, noviembre 2005

Amawtay Wasi, Libro Verde 2004: 216

CEAACES Acuerdo CEAACES-UINPI octubre 2 de 2013

CEAACES Resolución 003-0026 25 CEAACES-2012

CEAACES, Informe Final, p 10, 2013

\section{Referencias bibliográficas}

C.L.R. James (1989) The Black Jacobins: Toussaint L'Ouverture and the San Domingo Revolution. USA: Vintage

Coronel, V (2020) “La última guerra del siglo de las luces”: Revolución Liberal y formación del estado nacional en el Ecuador (1880-1926). Quito: Colección Atrio. FLACSO, (En prensa)

Coronel, Vy Cadahia, L. (2018) Luciana Populismo republicano: más allá de «Estado versus pueblo». Revista Nueva Sociedad (273), 72-82.

Conejo, A. 2008 Educación Intercultural Bilingüe en el Ecuador; Revista Alteridad, Vol. 3, No 2, 64-82.

Domenech, A. (2017). La democracia republicana fraternal y el socialismo con gorro frigio. La Habana: Ciencias Sociales

Figueroa, J. A. 2009 Realismo Mágico, Vallenato y Violencia Política en el Caribe Colombiano, Bogotá: ICANH. 
Figueroa, J. A. (2015) Educación superior intercultural y post-neoliberalismo en el Ecuador: el caso de la Universidad Amawtay Wasi. Pensamiento político y genealogía de la dignidad en América Latina., Edition: 1, Chapter: 3, Publisher: Maporrua Universidad Autónoma del Estado de México (UAEM), Editors: Guerrero Guerrero, Ana Luisa; Jorge Olvera García, Julio César Olvera García, pp.59-81

Guanche, J. (2017) ¿Quiénes somos todos? Prólogo a La democracia republicana fraternal y el socialismo con gorro frigio, de Antoni Domènech. La Habana:Ciencias Sociales.

Hornberger, N. (2000) Bilingual Education Policy and Practice en The Andes; Ideological Paradox and Intercultural Possibility. Anthroplogical and Education Quarterly. 31(2): 173-201.

Krainer, A. Guerra, D. Meiser, A. (2017) Educación superior intercultural y diálogo de saberes: el caso de la Amawtay Wasi en Ecuador. Rev. Educación Superior [online]. (vol.46, n.184), pp.55-76.

Martínez Novo, C. (2016) El desmantelamiento del Estado multicultural en el Ecuador en: Ecuador Debate, (o98) 35-50.

Martínez Novo, C. (2020). Intellectuals, NGOs, and Social Movements Under the Correa Regime: Collaborations and Estrangements. In: Sánchez F., Pachano S. (eds.) Assessing the Left Turn in Ecuador. Studies of the Americas. Palgrave Macmillan.

Mato, D. (2009) Educación Superior, colaboración intercultural y desarrollo sostenible/buen vivir. Experiencias en América Latina, Modalidades de colaboración, logros, innovaciones $y$ desafios. UNESCO, Iesalc.

Méndez, C. (2005). The Plebeian Culture The Huanta Rebellion and the Making of the Peruvian State 1820-185o Durham and London: Duke University Press.

Mosonyi, E. Gonzáles, O y Francisco R (1983). Fundamentos teóricos y programáticos de la educación bilingüe intercultural. Educación, etnias y descolonización en América Latina: Una guía para la educación bilingüe intercultural. Rodríguez, N. Masferrer, Vargas, R. México: UNESCO.

Muyulema Calle, A (1994) La quema de Ñucanchic Huasi. Los rostros discursivos del conflicto social en Cañar (Tesis de Maestría, Universidad Andina Simón Bolívar, Subsede Ecuador). http://repositorio.uasb.edu.ec/handle/10644/259o

Sanders, J. (2009). Ciudadanos de un pueblo libre: liberalismo popular y raza en el suroccidente de Colombia. Historia Crítica, (38),172-203.

Scott, R. (200o) Slave Emancipation in Cuba The Transition to Free Labor, 1860-1899 Pittsburgh: Latin American Series.

Sheller, M. (2012). Citizenship from Below Durham and London: Duke University Press.

Vélez, C. (2008). Trayectoria de la Educación Intercultural en el Ecuador. Revista Educación y Pedagogía, (XX, núm. 52), 103-112

Yanez Cossío, C. (1994). La Educación Indígena en el Ecuador. Quito, Ecuador: Instituto de Capacitación Municipal, Universidad Salesiana. 